\title{
Water awareness for sustainable local groundwater management
}

\author{
S. Hori \\ Graduate School of Global Environmental Studies, \\ Kyoto University, Japan
}

\begin{abstract}
Saijo city in the Ehime Prefecture, Japan, has an abundant supply of groundwater. Many local residents pump groundwater up from their own private well. This natural resource attracts both local people and the water industry. The environmental impact of groundwater is a matter of concern for local people. The survey made in 2008 showed that that those groundwater users try instinctively to pump it within sustainable limits. In this research, we make a hypothesis that local people have individual knowledge about their use of groundwater and if this is so, we need to use potential water awareness effectively in local water governance. Using water awareness for sustainable water management is crucial. We analysed the problem using an open ended questionnaire. People pointed out problems with salty water and muddy water from different locations. Those places show common characteristics. The local water awareness about muddy water was successfully used for local water management. Colon bacillus was detected afterwards. In this paper, we propose how to use water awareness for local water management.

Keywords: local groundwater management, water awareness, individual knowledge, open ended questions, Saijo city.
\end{abstract}

\section{Introduction}

Saijo city is nationally famous for its groundwater. The city has been chosen as one of the Select Best Waters in Japan, which was implemented by the Ministry of the Environment. In 2009, the City Hall began to consider revising the Saijo Groundwater Ordinance in order to cope with the new natural environmental problems in the future of both water quality and quantity. It shows unique 
environmental trends and difficulties with domestic water. Each household owns its private well in their garden. In other words, there is one well for domestic use for one household use. The users have their own experience about their well.

The consolidation of smaller municipalities - the old Toyo region, the old Komatu region, the old Tanbara region and the old Saijo region - has formed the New Saijo City since 2004. Most of citizens who live in the old Saijo region and the old Toyo region pump groundwater up from their garden for their domestic use. Hence, they notice the changes in both quantity and quality of their private well water. This comes from their daily experience. We propose a hypothesis that local people have individual knowledge about using their groundwater and if this is so, we need to include their potential water awareness effectively into the local water governance. Water awareness is one sort of individual knowledge. Arcury [1] called this water awareness as environmental knowledge. Arcury also proved how environmental knowledge can achieve results for the individual. According to Arcury [1], increased knowledge about the environment is assumed to change attitudes and both environmental knowledge and attitudes are assumed to influence environmental policy. Environmental knowledge is found to be consistently and positively related to environmental attitudes. With the correlation of knowledge and attitudes, the low level of environmental knowledge has disturbing implications for environmental policy [1]. The goal of this paper is the development of a water awareness methodology which can be applied in practice to water governance: (1) to have a new understanding of individual knowledge and awareness related to water, and (2) to have one administrative body applying this analysis of water awareness into local policy in the future.

\section{Methodology}

This study includes an analysis of questionnaires for city residents living in Saijo city in 2008, and the field study we implemented in 2009. From the standpoint of water awareness, we focus on the answers given by local people about water awareness obtained by an open ended questionnaire. Open ended questions are ones that require more than one word answers. All open ended questions are alike in that the respondent is not given a choice of answers. However, the reasons for using this structure and the level of cognitive effort needed to respond to the question can vary. The answer could come in the form of a list, a few sentences or something longer such as paragraph or essay. Open ended questions require a response with more depth and length. Open ended questions are also helpful in finding out more about a given situation. The open ended question does not provide categories of answers [2].

The city questionnaire was a random sample of 5000 citizens over 20 years old, which was sent by post. $40.78 \%$ of Saijo citizens answered the questionnaires. The details are below:

- $\quad$ Sijo region; 1,078/2,582 citizens,

- Toyo region; 517/1,435 citizens, 
- Tanbara region; 230/583 citizens,

- $\quad$ Komatu region; 159/1, 435 citizens.

There are two factors revealed by open ended questions about local groundwater issues in Saijo city. There were several points in common. The most interesting of this answer was about salty water and muddy water. We give the location address of where the respondent answers lived at that time. The results are displayed on a map using a Graphical Information System (GIS); we pinpointed the area using zip codes. This information suggests the importance of using the information about water awareness for local and rural water management.

This analysis is motivated by building a new framework for a local water administration policy. It aims to allow that individual water knowledge and awareness contribute democratically to society. The open ended question methodology is the initial stage of the study.

\section{Description of the study area}

Saijo City covers an area of 509.07 square kilometres. The east-west distance is $29.71 \mathrm{~km}$, and north-south distance is $25.86 \mathrm{~km}$ at their maximum. The city is the third largest city in the Ehime Prefecture. In the South there is the peak of the Ishizuchi Mountains, and it is the highest peak in Western Japan. On the other side of the city is the Seto inland sea of Japan. The city is located at 133 degree 11 minutes longitude east and 33 degree 51 minutes north.

The total population of the city is 113,845 (March, 2013) and total number of households is 48,463 . The total population of Ehime Prefecture is 1,441 million. New Saijo city was formed on November 1st in 2004 by the consolidation of old Saijo city, Toyo city, Tanbara city and Komatu city. The north part of the city had been increased by the construction of artificial tidal lands.

The city is located in the eastern part of Ehime Prefecture on the Douzen Plain. The total city area is $231 \mathrm{~km}^{2}$. Mountains form about $73 \%$ and the rest is an open sea area, of which the coastal industrial zone is about $27 \%$. The whole south part of the Saijo Plain and the western part are one mountainous zone in front of the Peaks of Ishizuchi, which at 1982 meters above sea level are the highest mountains in West Japan. The other zone is gentle flat land with the city area and an agriculture zone. The Nakayama and Kamo Rivers flow into the city from the mountain zone. The total flat area is about $509.05 \mathrm{~km}^{2}$, of which $30 \%$ is a residential region and $70 \%$ is forests and fields. A boundary is formed by between flat zone and mountain zone by the Okamura dislocation. Along this dislocation, there is a clear line structure and the topography changes from East-North-East to West-South-East. The boundary between the seaside and the inland side has been affected by the distribution of groundwater. The inland side between the estimated dislocation and the Okamura dislocation has been formed by belt of subsidence due to the activities of some faults and that grew as a huge reservoir for groundwater resources. 


\section{Hydrological regime}

Ehime prefecture has three climate divisions; Seto inland sea climate, Pacific coast climate, and Mountain climate. The surrounding small islands of Shikoku islands and the coastal area are Seto inland sea climate. The mean annual precipitation is about 1,200-1,600 $\mathrm{mm}$. That climate has a relatively warm climate. The average yearly temperature at the region is about 15 16 degrees. The north part of mountains in Ehime prefecture is part of mountain climate. The annual precipitation is $1,900-2,000 \mathrm{~mm}$. The average yearly temperature is 12-14 degrees. Saijo city belongs to the Seto inland sea climate, which has only a little rain. However, due to the blessings of the neighbouring mountain range this area is abounds in groundwater. Rain falling in the mountain region becomes the river water of the Kamo River. This has its source in the Peak of the Ishizuchi Mountains. The rainwater penetrates through the riverbed and the old river line around the entrance of the flat land into the ground. Therefore, the groundwater of the Saijo Plain has a close correlation with the rainfall on the mountain region. The mean annual precipitation of on the plains is about $1,334 \mathrm{~mm}$. The mean annual precipitation on mountain region is estimated 2,294 $\mathrm{mm}$, which is about 1.7 times as large as annual precipitation on the plains.

\section{Answers on domestic use}

The age distribution of those answering the questionnaire was as follows:

\begin{tabular}{lr} 
In the $80 \mathrm{~s}$ & $9 \%$ \\
In the $70 \mathrm{~s}$ & $18 \%$ \\
In the $60 \mathrm{~s}$ & $22 \%$ \\
In the $50 \mathrm{~s}$ & $19 \%$ \\
In the $40 \mathrm{~s}$ & $12 \%$ \\
In the $30 \mathrm{~s}$ & $11 \%$ \\
In the $20 \mathrm{~s}$ & $8 \%$ \\
No answer & $1 \%$ \\
\hline
\end{tabular}

Of those who answered were:

\begin{tabular}{lr} 
Female & $52 \%$ \\
Male & $47 \%$ \\
No answer & $1 \%$ \\
\hline
\end{tabular}

The number of years those who answered had lived in the city:

\begin{tabular}{lc} 
Over 30 years & $50 \%$ \\
20 to 29 years & $16 \%$ \\
10 to 19 years & $14 \%$ \\
5 to 9 years & $8 \%$ \\
1 to 4 years & $7 \%$ \\
Within 1 year & $4 \%$ \\
No answer & $1 \%$ \\
\hline
\end{tabular}


Of those who answered what water supply they used:

$\begin{array}{lcccc}\text { Region } & \text { Old Tanbara } & \text { Old Komatu } & \text { Old Saijo } & \text { Old Toyo } \\ \text { Only use groundwater } & 17 \% & 9 \% & 66 \% & 41 \% \\ \text { Only use the public water supply } & 69 \% & 66 \% & 26 \% & 42 \% \\ \text { Use both } & 12 \% & 24 \% & 6 \% & 16 \% \\ \text { Others } & 2 \% & 1 \% & 2 \% & 1 \%\end{array}$

Some people use both the public water supply and groundwater because of groundwater contamination. The public water supply is used for drinking and groundwater is used mainly for laundry, showering and bathing.

According to the city report published in 2000, the citizens in the old Saijo city used only private household groundwater, except for a part of the mountain region.

The percentages for the domestic use of water in 2000 were:

Only use groundwater $\quad 73 \%$

Only use the public water supply $\quad 26 \%$

Others $1 \%$

$100 \%$

The total percentage of the answers from old Saijo region, which was formed the old Saijo city, showed almost the same proportions. Therefore, the results from questionnaire could minimize errors in calculating the current situation.

\section{Water awareness}

There are many ongoing discussions about how water awareness among residents influences water governance against the city policy. To examine this issue, we collected 2,039 answers from Saijo citizens by open ended questions; "Please write your individual knowledge or awareness about your private well," which had given to Saijo citizens in 2008. Our results suggest that local people should influence the city's water governance with their potential water awareness based on their experience of everyday life.

As an example, Table 1 shows answers to the open ended questions from people who live or work in old Saijo city. The amount of each written answer itself was obviously small; on the other hand, the details of written answer are what we have to focus on in order to identify the local water situation. Negative opinions are easier to collect than positive in this case. The analyst should choose dominant answers to have an effect on a sustainable water policy in an early stage. That is to ensure the operation of the administration which truly reflects the popular will.

This research selected results from two places located on the artesian aquifer in the area of the seaside. If something threatens the life of inhabitants directly, an analyst should use a sample survey to emphasize the problems that need to be managed. There was no standard pattern for applying the management and conservation of groundwater. Water awareness can be applied for sustainable solutions for its preservation and mitigation. 
Table 1: Answers in old Saijo city.

\begin{tabular}{|l|l|}
\hline Answers & The number of respondents \\
\hline Well water tastes saltier & 3 \\
\hline After the dam construction, I feel the water well is decreasing & 4 \\
\hline The well often runs dry & 1 \\
\hline Well water ran dry only in summer & 9 \\
\hline I am worried about water quantity for the next generations & 1 \\
\hline There are impure ingredients with sand & 3 \\
\hline I feel the well water level dropped down & 1 \\
\hline Well water tasted more smoothly when I was a child & 1 \\
\hline Well water tastes iron & \\
\hline Well water tastes like stench of sewage & 2 \\
\hline I am worried about water quality & 4 \\
\hline $\begin{array}{l}\text { There is a garbage yard in the mountain; I think it influences } \\
\text { water quality }\end{array}$ & 1 \\
\hline The groundwater is getting muddy & 5 \\
\hline The water pressure of our well is getting weak & 7 \\
\hline Well water temperature becomes gradually higher & 1 \\
\hline Well water stinks when the water pressure becomes lower & 1 \\
\hline Well water is not tasty anymore & 4 \\
\hline Well water contains alga & 1 \\
\hline The well e dried up & 1 \\
\hline Coliform was detected in our well & 1 \\
\hline
\end{tabular}

\subsection{Awareness based on daily experiences}

People raise their awareness based on their daily experiences. For example, "my well dried up in the summer", "the water temperature becomes gradually higher", "the groundwater is getting muddy", and "our well tastes saltier". We experience and understand the world through signals that are received by our senses and interpreted by the brain. Therefore, experiences raise the individual awareness.

\subsection{Awareness based on both daily experiences and self-taught knowledge}

People understand and begin to study new Individual knowledge based on selftaught knowledge, transcendental knowledge, specialized knowledge and other knowledge. Water awareness may be a figment of their imagination based on individual knowledge. For example, "I am worried about sustainable water quantity ", "there is a garbage yard in the mountain; I think it influences water quality", "I am worried about the amount of water taken from groundwater by the coastal industrial zone." and "after the earthquake, the water became muddy" etc. As we explained, those answers had reflected their own opinions related to water environmental issues. Hence, people raise their individual knowledge, and it was analysed by each user level. 


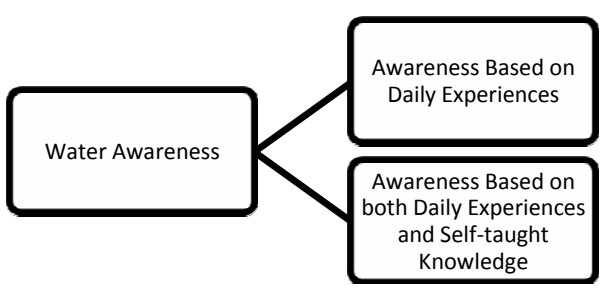

Figure 1: $\quad$ Water awareness.

\section{Geographical analysis on water awareness}

How we could use water awareness for local water management and reflect on local water policy? We selected two answers to our open ended questionnaire; "groundwater from our well tastes salt", and "the condition of groundwater is becoming muddy”.

The answered locations that gave those answers are identified by zip codes. This survey has shown how to analyse water awareness in practice.

The first survey gives the places where they answered about salt damages. It shows that we received information about salty water damages from some area of the downstream area of Kamo River. According to the field survey and the open-ended questionnaire, some rice farmers complained that they are no longer able to cultivate rice on some land along Kamo River. A few agricultural farmers reported salt damage in the interview in 2009. The region of the seashore has a direct influence on the infiltration of salt from the sea. Recently, "Ice Plant", Mesembryanthemum crystallinum, which is able to grow up in high salinity soil, became a new arrival in a community store.

The second survey indicates the location of muddy water damages. In old-Saijo region, there are several places that answered the open-ended questions with the groundwater tastes oozy, stinks or is muddy. Those locations are often places which are right next to the riverside on the map. Escherichia coli was detected afterwards by chemical analysis close to riverbank. This result was brought on local groundwater conservation management in administrative level. Water awareness collected by open ended questions should be proved by scientific investigations before using individual knowledge for local water governance in general.

\section{Conclusions}

Using water awareness is the next challenging step for to implementing sustainable water governance in Japan. It has been thought that it takes time for water awareness to be reflected in local water policy. The attempt to improve public participation in taking environmental decisions should strive to develop mechanisms and forums of engagement that emphasize civic discovery through which citizens test and create social knowledge in order to uncover, assess, and 
resolve shared problems [3]. These is research results show that when the locations of problems with water are clearly shown, local government should the use civic water awareness for groundwater conservation and mitigate serious issues which arise in a practical manner. The exchange of information between citizens and local government would encourage an effective governance and management of water. The goal of this research is the development of a new methodology for applying water awareness to water management into society at the early stage of a groundwater revolution at a local groundwater management level.

\section{References}

[1] Arcury, T. A., Environmental attitude and environmental knowledge. Human Organization. 49(4): p. 300, 1990.

[2] Ballow, J., Open-Ended Questions. Encyclopaedia of Survey Research Method, 2011.

[3] Depoe, S. P., et al. Communication and public participation in environmental decision-making. State University of New York: p. 10, 2004. 